will this require some form of training? This is certainly an interesting and unexplored field that has scope for many daily uses and may even strengthen our future relation with ENT specialists whom we would potentially work closely with to construct such devices.

R. S. Virdi

Glasgow

1. Sonitus Medical, 2011. Hearing Device Innovation - About SoundBite. [online] Available at: http:// www.sonitusmedical.com/product/ (accessed 18 March 2011)

2. Endgadget, 2011. SoundBite dental hearing aid receives European approval - Engadget. [online] (updated 15 March 2011). Available at http://www. engadget.com/2011/03/15/soundbite-dental-hearing-aid-receives-european-approval/ (accessed 18 March 2011)

DOI: 10.1038/sj.bdj.2011.391

\section{CLEFT PATHWAYS}

Sir, the study by Locke and Bishop ${ }^{1}$ has thrown up some important issues that I would like to highlight. Having worked in a variety of restorative units over the last seven years I am sensitive to the difficulties in the provision of multidisciplinary treatment for cleft lip and palate patients whilst in their adolescent years but what is more worrying is the need for ongoing care past the age of 18 .

The care pathways outlined for cleft lip and palate seem to decline once both orthodontic and surgical treatment has been completed at the end of growth and Clinical Standards Advisory Group (CSAG) audit requirements have been met. However, for many patients this period is not the end of their care but rather the start of a lifelong commitment and support from restorative specialist teams. Sadly this need may not be as accessible as current need requires.

Once formal cleft treatment is completed patients can be forgiven for being relieved due to the number of hospital visits and surgical episodes required for correction of their abnormality. Once into adulthood the ongoing maintenance and management of these patients who may present with complex problems that are otherwise unmanageable in primary care can fall on the specialist in restorative dentistry. Teeth in cleft patients have been shown to have a plethora of morphological anomalies ${ }^{2}$ in addition to compromised periodontal health due to proximity to the cleft. ${ }^{3}$ Where surgical correction of the cleft has been suboptimal the requirement for obturator provision as opposed to further surgery may be preferred. A newer issue is the ongoing maintenance of implant prostheses. These issues have not been addressed formally for patients leaving the cleft pathway. In contrast the requirement of a specialist in restorative dentistry for the initial assessment, treatment and ongoing monitoring of patients with head and neck cancer has been documented in national clinical guidelines. ${ }^{4}$ The figures for this patient cohort are slightly better than the results from the current Locke and Bishop study - although there is still an obvious requirement for improvement.

There is a need for the specialty of restorative dentistry in the lifelong treatment of these patients which needs to be highlighted for health care commissioners and CSAG.

A. Alani

1. Locke M, Bishop K. An assessment of the contribution of UK specialists in restorative dentistry to cleft lip and palate services. Br Dent J advance online publication, 4 March 2011 (DOI 10.1038/ sj.bdj.2011.142).

2. Al Jamal G A, Hazza'a A M, Rawashdeh M A Prevalence of dental anomalies in a population of cleft lip and palate patients. Cleft Palate Craniofac J 2010; 47: 413-420.

3. Huynh-Ba G, Brägger U, Zwahlen $M$, Lang N $P_{\text {, }}$ Salvi G E. Periodontal disease progression in subjects with orofacial clefts over a 25-year follow-up period. J Clin Periodontol 2009; 36: 836-842.

4. Alani A, Owens J, Dewan K, Summerwill A. A national survey of oral and maxillofacial surgeons' attitudes towards the treatment and dental rehabilitation of oral cancer patients. Br Dent J 2009; 207: E21

DOI: $10.1038 /$ sj.bdj.2011.392

\section{ANIMAL ETHICS}

Sir, I was very inspired at the fact that the winner of the prestigious BDA/Dentsply Student Clinical Programme was Deema Marzouq for her poster on ethical issues within periodontics. Periodontal regeneration is an area of intense research, however, often we do not consider that some products take proteins (eg amelogenin) from developing animals' tooth germ. Animal ethics should be considered an important factor when deciding which regenerative procedure to use. We must know just how many animals were used for the sake of one periodontal pocket.

H. Shah

Student, King's College London DOI: 10.1038/sj.bdj.2011.393 